\title{
Solar Powered Ventilation System for Parked Car
}

\author{
Ibtehal M. Mishal \\ Al-Balqa Applied University \\ Computer Engineering \\ Department
}

\author{
Mai S. Abubaqar \\ Al-Balqa Applied University \\ Computer Engineering \\ Department
}

\author{
Razan H. Hiasat \\ Al-Balqa Applied University \\ Computer Engineering \\ Department
}

\begin{abstract}
The difference in temperature between the interior of the car and its exterior can rise up to $30^{\circ} \mathrm{c}$ which may have a threatening effect on humans and pets if they were left unattended inside the car, especially during summer, the reason behind such difference in temperature can be the result of the heat radiation and absorption.

This paper reviews a solar car ventilation system and its effectiveness in reducing the temperature of the car interior when it is parked under the direct sunlight. The commercially available ventilators won't decrease the car cabin to the required temperature. The proposed new ventilation system can reduce the interior temperature of the car cabin up to $17 \mathrm{C}^{\mathrm{o}}$; the proposed system uses solar power energy to lower fuel consumption, as well as carbon dioxide emission and engine load. So this paper explains the concept behind the proposed ventilation system and the method used for temperature reduction.
\end{abstract}

\section{Keywords}

Solar Power, Car Ventilation, Temperature

\section{INTRODUCTION}

The interior temperature of a car cabin parked under direct sunlight, can reach up to critically dangerous levels. This phenomenon is called "Greenhouse Effect". Sunlight reaches earth In the form of visible, ultraviolet and nearinfrared radiation ,while most of the solar energy is reflected before arriving the surface of the earth; the visible portion of the spectrum passes through the atmosphere into the earth surface, where sunlight can be absorbed by cars exterior which results in Heating the car as shown in the figure 1. [1] [16]

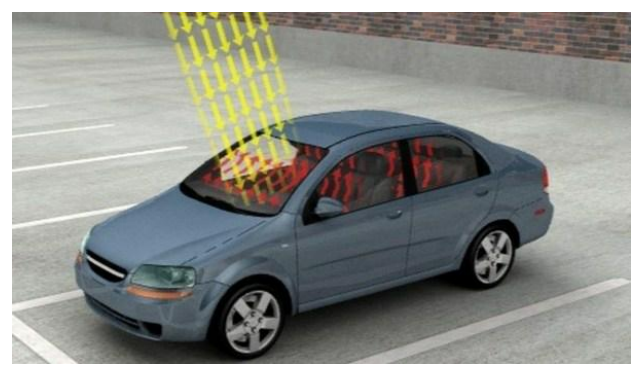

Figure 1: Greenhouse example on cars

Objects radiate energy as a function of the body temperature ; human beings radiates energy in the infrared spectrum while having the approximate body temperature of $37^{\circ}$.human eyes in insensitive to the infrared light spectrum and thus cannot see that radiated energy ,however ;such radiation can be detected by some special equipments such as special night vision cameras and goggles . [1]. Therefore, sunlight that shines on the car objects inside the car (carpet, plastic parts etc ) thereupon that energy is re-radiated in the infrared spectrum. While water moisture and carbon oxide in the air within the cabin absorbs this re-radiated infrared energy, hence continuously accumulating the heat. This heat is trapped indoors with no escape route.

The car operates as a greenhouse when sunlight enters through the car's windows, heating up the objects inside the cabin (seats, dashboard, and any other object). Those objects radiates energy, which heats up the interior air by means of both conduction and convection. The external temperature needed to invoke such a threatening effect does not need to be very high on a $21^{\circ} \mathrm{C}$ degree day, the car temperature can rise up to $46^{\circ} \mathrm{C}$ range ,harmful for any living organism, specially the elderly, kids and pets.[2] The color of the car's interior is one of the most impacting factors in heating up the automobile's cabin .Darker shades increase the speed of the heating process, some studies shows that there is a imperceptible difference between fabric and leather seats. However the color of the exterior hardly makes a difference. Cars having a sunroof tend to heat up faster as well, since a sunroof is just another window for the sunlight to pass through. [2]

\section{GENERAL TEMPERATURE PROFILE WITHIN THE CAR PARKED IN DIRECT SUNLIGHT}

Table 1: General temperature

\begin{tabular}{|l|l|l|}
\hline $\begin{array}{l}\text { Time } \\
\text { duration }\end{array}$ & $\begin{array}{l}\text { Exterior } \\
\text { Temperature } \\
\left({ }^{\mathbf{C}} \mathbf{C}\right)\end{array}$ & $\begin{array}{l}\text { Interior } \\
\text { Temperature }\left({ }^{\mathbf{}} \mathbf{C}\right)\end{array}$ \\
\hline $\begin{array}{l}10 \\
\text { minutes }\end{array}$ & 30 & 43 \\
\hline $\begin{array}{l}20 \\
\text { minutes }\end{array}$ & 38 & 48 \\
\hline $\begin{array}{l}30 \\
\text { minutes }\end{array}$ & 32 & 51 \\
\hline $\begin{array}{l}60 \\
\text { minutes }\end{array}$ & 40 & 56 \\
\hline $\begin{array}{l}90 \\
\text { minutes }\end{array}$ & 41 & 59 \\
\hline
\end{tabular}

- Leaving children or pets unattended in the car cabin can be a fatally dangerous mistake, regardless of the time duration. partially opening the window help the re-radiated energy escape from the car cabin without energizing water moisture and carbon oxide trapped inside .[1][16] 


\section{EFFECTS OF PARKING UNDER SUNLIGHT}

Leaving children, elderly people or persons with disabilities on their own in vehicles can result in a heat stroke, even if the windows are partially left open. Since they may not be able to express their verbal discomfort

The risk of heat stroke in cars is higher for pets than for humans, as dogs, cats and many other animals only perspire in limited areas of their bodies. Many dogs are accompanied by the blind in many institutions, and the opening of the window of the vehicle sufficiently may represent an opportunity to escape or expose others to bite

At least 500 children died in the United States from 1998 to 2011 due to being left in a very hot car, with only $75 \%$ of those aged over two years. When the temperature outside the car is 70 degrees Fahrenheit (21 degrees Celsius), the temperature inside the car exceeds 120 degrees (84.4 degrees Celsius), even if the windows are shaky.The prosecution of parents varies widely. An example of this is what happened to a university professor in California, where his son was forgotten in a hightemperature car and the head of a horse trainer in Florida left his daughter in a very hot car. In both cases, the child died unintentionally, but the university professor was never tried, and the horse trainer spent 20 years in prison. Of the many cases of child death in high-temperature cars, about half are due to parents forgetting their children in cars, while $18 \%$ occur as a result of deliberately leaving children in cars without realizing the seriousness of the situation, and those who die as a result of entering the car for play $30 \%$. Also , The maintenance of perfumes, lighters in general the flammable materials inside the vehicles in the summer is a great danger due to exposure to high temperature and pressure due to lack of ventilation inside the car, which may lead to the explosion has provided a solution to all these problems.[16]

\section{RELATED WORKS}

Khan M.U et al, (1991) in [14] developed a system of ventilation to limit the car cabin temperature under the hot sun. From Figure 3 it shows the different temperatures at the top of the front panel and at the air temperature near driver head. Because These two places are the two highest temperatures in the car cabin.

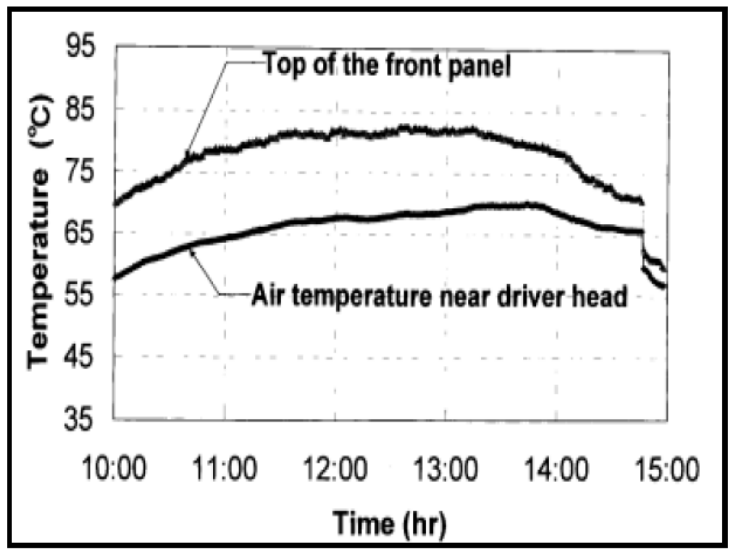

Figure 3: Temperature variation with the time at different locations
In addition to that, Bjorn Jenssen Wachenfldt et al, (2006) in [15] investigated about air flow rate and energy saving potential in school with demand controlled displacement ventilation. Figure .4 shown the heating temperature against volume flow rate, the efficiency is dropping with the flow rate of ventilation is increasing. The heat in a room is continuous replaced by fresh air from outside so the energy loss because of the heat is being transfer out during the ventilation blower is running. From this concept, the ventilation process could reduce the temperature inside the room of a car when parking under the sun. The main reason is the reduce heat recovery efficiency for the higher airflow rate.

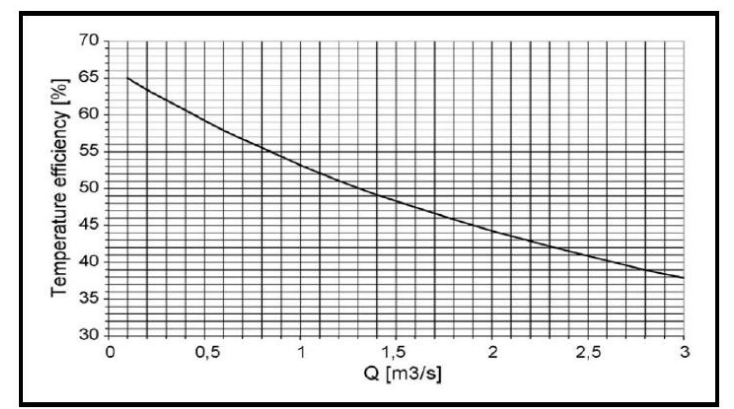

Figure 4: The Diagram of Percentage Temperatures Efficiency versus Flow RateQ BJORN JENSSEN WACHENFELDT

Finally, Alen (2006) developed Volvo's flagship S80 sedan includes a Personal Car Communicator that can sense if there is a heartbeat inside the car and send a warning message to the driver's wireless key fob. Volvo is marketing it as a safety option for women worried about back-seat attackers, not as a way to remind the driver that there is somebody left inside the car . There is no protected system at all.

\section{THE PROPOSED SYSTEM}

The objective of this paper is to find a solution to the problem of high temperatures inside the vehicles and the lack of oxygen by making a smart system that starts automatically to ventilate the car inside if the temperature increased to a specified point while parking in the sun light ,the good thing that the power needed to start the ventilation is taken from the sun light using some specific solar panels

Because preventing the problems before happening is much better and less expensive than solving the damages after, we will save the money on fixing the car if the temperature exceeds the specified point.

This paper works on monitoring the temperature levels of the car while parking, if it exceeds the normal level, the system will start his work to ventilate the car and keep it in the normal range.

\subsection{Car model}

Car Model needed to monitoring the temperature levels of the car while parking, if it exceed the normal level, the system will start his work to ventilate the car and keep it in the normal range. So to obtain the functions of car model, it must consist of the following, as shown in figure 5 .

1.Solar thermal collector unit: converts the energy of light directly into electricity by the photovoltaic effect.

2. Adjusting temperature unit: adjust suitable 
temperature in vehicle.

3.Display unit: it shows the in temperature and out temperature.

4.Temperature measurement unit: it measures the temperature inside a vehicle and outside.

5.Motion unit: used to cover the fan.

6.Battery unit: to be re-charged and charge thousands of times and provide high currents for a brief amount of time.

1.Cooling unit: to cool the inside vehicle.

2.Control unit: this unit is needed to control the designed system and to connect the units inside a vehicle.

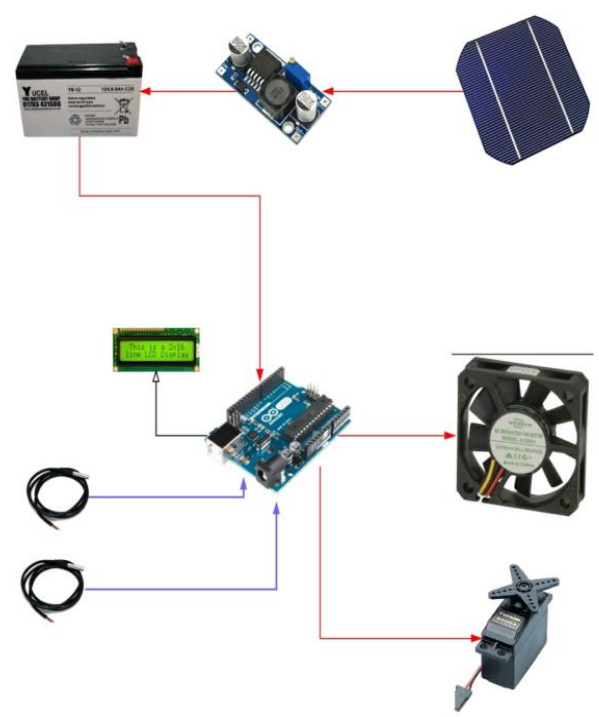

Figure 5: Car model

\section{THE PROPOSED SYSTEM DESIGN}

To implement car model in a correct hardware implementation the following components are used

- The Arduino Uno R3 to implement control unit in car model.

- Two Temperature Sensor, one for measure the temperature inside vehicle, and one for outside.

- Step-up converter is an electric power converter.

- LCD for display unit needed in car model.

- Fan: for cooling the car

- Solar cell to detecting light or other electromagnetic radiation near the visible range, or measuring light intensity.

- $\quad$ Servo motor to cover the fan duct.

- Lead acid battery to provide high currents for a brief amount of time to start an engine.

- IFR 520 MOSFET transistor to provide a low cost way to drive a DC motor

So, the complete design for Car Model can be implemented as shown in figure 6 .

The proposed system automatically checks the temperature inside the car then compares it with the stored temperature to control the DC fan speed according to the readings and then displays these parameter changes on a LCD display. This is accomplished by data communication between Arduino, LCD, temperature sensor Module and DC fan that is controlled through PWM technique by which we can control voltage.

Control unit executes the program whose flowchart is described in figure 7. Readings are taken from the internal temperature sensor, and if the temperature is greater than $26^{\circ}$ the fan start working on either fast or normal speed according to temperature difference.

Operation procedure:

1. The sun light will be converted to voltage and stored in the car battery, which means that this power can be used later on by the car electronics, which will save the fuel by preventing the car generator from being use.

2. The system will measure the inner temperature of the car and compare it with the outer temperature and it will start the ventilation fan automatically if desired

3. The system can measure the battery voltage and it will automatically stop the system in case of low battery to avoid reaching died battery

4. All the measured data will be displayed on the liquid crystal display to the driver, this data includes the inner and outer temperature also the battery voltage

5. A servo motor will be used to cover the fan duct if the system is not working, this will avoid the air from being entering the car through the ventilation duct

\section{CONCLUSIONS}

After performing test procedure using the same car before using the proposed system and after installing it; the following conclusions was obtained:

1. In the cases where the system was not used, the temperature reached $65^{\circ} \mathrm{C}$ which can be considered as a high temperature inside the car and it may have serious effects on the car interior and such increase in the temperature needs a relatively long time for the car air conditioning system to decrease it.

2. The Maximum temperature measured inside the car was $65^{\circ} \mathrm{C}$ even though the external temperature was approximately $40^{\circ} \mathrm{C}$.

3. When the system was installed the battery voltage was not affected which means that the solar cell covered all the consumed energy by the system .

4. During system operation the internal temperature never rose above the $43^{\circ} \mathrm{C}$ level which conclude that the proposed system is sufficient and reliable in practice.

5. The proposed system does not affect the car battery in consideration that the solar cell covered the system consumed power.

6. After operating the system for multiple times the system operation was relatively flawless and was functioning with minimal error readings. 


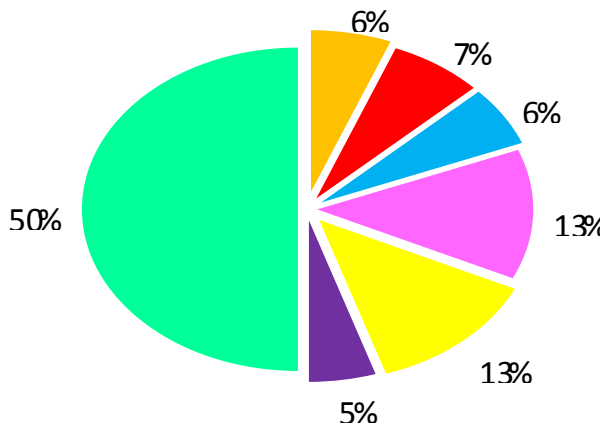

Figure 2: Type of accidents

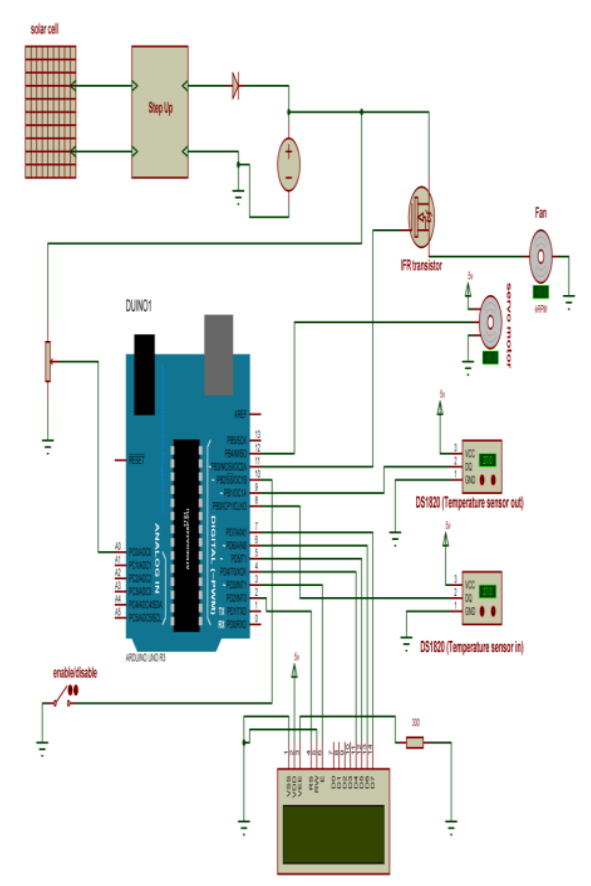

Figure 6: Complete design of Car Model .

\section{REFERENCES}

[1] https://www.scientificamerican.com/article/howexactly-does-light-tr/

[2] http://steve.cooleysekula.net/blog/2011/08/16/thegreenhouse-effect-part-2-hot-car-hot-earth/

[3] https://www.walmart.com/browse/auto-tires/car-sunshades/91083

[4] https://techcrunch.com/2014/09/24/the-first-fourseater-solar-powered-vehicle-hits-the-u-s-road/

[5] https://www.solarquotes.com.au/panels/photovoltaic/

[6] https://solartribune.com/solar-panels-efficiency

[7] https://mozaw.com/monocrystalline-vspolycrystalline-solar-panels/

[8] https://blog.pickmysolar.com/monocrystalline-solarpanels-polycrystalline-comparison

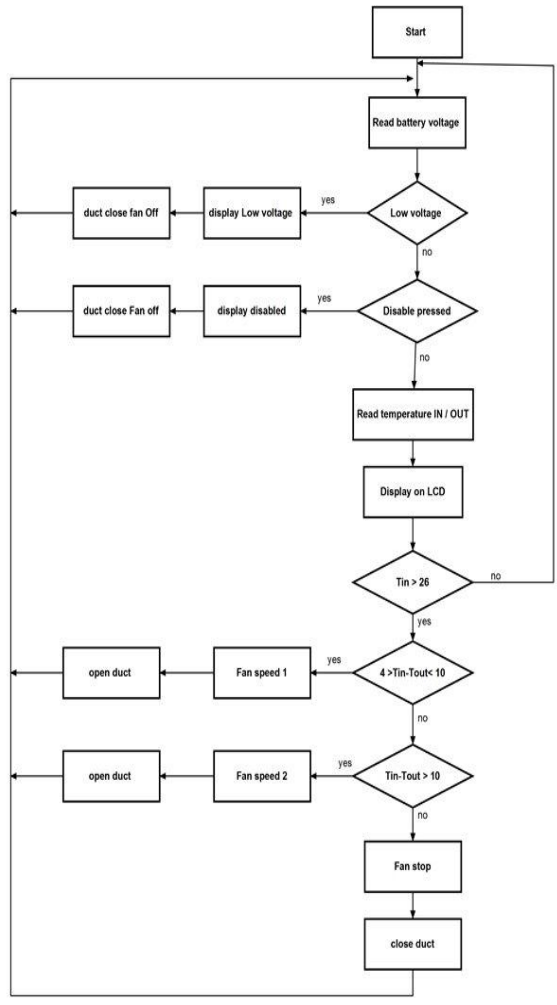

Figure 7: Flowchart of the system

[9] https://www.solarpowerworldonline.com/2015/08/wh at-is-the-best-type-of-battery-for-solar-storage/

[10] https://www.wbdg.org/resources/solar-ventilation-airpreheating

[11] https://www.jameco.com/jameco/workshop/howitwor ks/how-servo-motors-work.htm

[12] https://circuitdigest.com/microcontrollerprojects/automatic-temperature-controlled-fan-project

[13] http://nevonprojects.com/sun-tracking-solar-panelusing-arduino/

[14] Khan M.U, "Development of Ventilation Technique To Limit The Car Cabin Temperature Under a Blazing Sun," Universitoy f Toyama, Jepun, 1999.

[15] Bjorn jenssen wachenfeldt, Mads Mysen, Peter G. Schild., "Air Flow Rate and Energy saving potential in schools with Demand Controlled Displacement 
Ventilation," , New York, United Stated Of Amarica, 2006, pp. 1073-1079.|

[16] Mike Schwartz, "Medical experts emphasize risk of leaving children in locked cars SAFETY:A closed vehicle "becomes an oven" in hot weather, a Loma Linda physician say", The Press-Enterprise, July 3,
Volume 179 - No.47, June 2018

2001.

[17] Simon Roberts, Solar Electricity : A Practical Guide to Designing and Installing small Photovoltaic System, 1st ed. Prentice Hall International (UK) Ltd, United Kindom:Printed in Great Britain at the Universiti Press, Cambridge, 1991. 